\title{
As diretrizes curriculares nacionais da educação física de 2018 e as imprecisões em torno da saúde coletiva e o SUS
}

\author{
the $\mathbf{2 0 1 8}$ national curriculum guidelines for Physical \\ Education and the inaccuracies surrounding public \\ health and the SUS
}

\section{Las directivas curriculares nacionales de la Educación Física de 2018 y las inexactitudes en torno de la salud colectiva y del SUS}

\author{
(iD) Leonardo Trápaga Abib \\ Universidade Federal do Espírito Santo, Vitória, Espírito Santo, Brasil \\ e-mail: leoabib@gmail.com \\ iD) Alan Goularte Knuth \\ Universidade Federal do Rio Grande, Rio Grande, Rio Grande do Sul, Brasil \\ e-mail: alan_knuth@yahoo.com.br
}

Resumo: O presente ensaio apresenta uma análise e discute sobre a emergência, os limites, imprecisões e as abordagens de saúde presentes nas novas diretrizes curriculares nacionais da educação física, instituídas pela resolução CNE/CES n 6/2018. O documento carrega em si distintas perspectivas de saúde, o que não permite entender o quanto e de que formas se enfatizará o debate sobre SUS e a saúde coletiva. Embora inclua essas temáticas, a resolução demonstra pouca articulação com as políticas de formação na área da saúde, deixando lacunas em aspectos como a integração ensino-serviço-comunidade, a interprofissionalidade, noções de cuidado e perspectivas de atuação profissional.

Palavras-chave: Educação Física; Diretrizes Curriculares; Saúde Coletiva; Sistema Único de Saúde. 
Abstract: This essay presents an analysis about the emergency, limits, inaccuracies and health approaches present in the new national curriculum guidelines for Physical Education, proposed in resolution CNE / CES $n^{\circ}$ $6 / 2018$. The document contains different health perspectives, which does not allow the understanding of how much and in what ways the debate on SUS and collective health is emphasized. Although it includes these themes, the resolution shows little interaction with the training policies in the health area, leaving gaps in aspects such as the teachingpolicy-community integration, interprofessionality, care concepts and perspectives of professional performance.

Keywords: Physical Education; Curriculum Guidelines; Public Health; Unified Health System.

Resumen: Este ensayo presenta un análisis y discusión sobre la emergencia, los límites, las inexactitudes y los enfoques de salud presentes en las nuevas directivas curriculares nacionales de Educación Física, instituidos por la resolución CNE/CES n 6/2018. El documento lleva consigo diferentes perspectivas en salud, lo que no nos permite entender cuánto y de qué manera se enfatizará el debate sobre el SUS y la salud pública. Si bien incluye estos temas, la resolución muestra poca articulación con las políticas de formación en el área de la salud, dejando vacíos en aspectos como la integración enseñanza-servicio-comunidad, la interprofesionalidad, las nociones de cuidado y las perspectivas de desempeño profesional.

Palabras-clave: Educación Física; Directivas Curriculares; Salud Colectiva; Sistema Único de Salud.

Submetido em: 22-12-2020

Aceito em: 12-04-2021 
As diretrizes curriculares nacionais da educação física de 2018 e as imprecisões em torno... Leonardo Trápaga Abib • Alan Goularte Knuth

\section{Considerações iniciais}

Passada pouco mais de uma década da implementação das diretrizes curriculares nacionais para os cursos de educação física - Resolução CNE/CES no 07/2004 -, o campo acadêmico e profissional da área retoma a discussão em torno de sua revisão, readequação ou ainda uma possível superação. Ao longo dos últimos anos ocorreram muitos debates públiços durante eventos, tanto de caráter local quanto nacional, sobre a implementação dessas diretrizes e os seus impactos na e para formação inicial, demonstrando que o tema repercute e reverbera na área, dados os desafios para a construção dos currículos nas instituições de ensino superior.

As produções acadêmicas vêm apontando, por um lado, diversas críticas às bases epistemológicas que embasaram a resolução que até pouco estava em vigência, assim como o caráter pró-mercado e corporativista que teria tal resolução. Por outro lado, análises mais brandas apresentam argumentos favoráveis à divisão dos cursos de graduação em licenciatura e bacharelado, afirmando que assim trariam melhor formação, tanto para o campo da escola quanto para os demais campos de atuação profissional (FINOQUETO, 2013; MAIA; SACARDO, 2020; SOUZA NETO et al., 2016).

Fruto desse processo de debates, produções e discussões, as novas diretrizes curriculares nacionais para os cursos de educação física - DCNEF são instituídas no ano de 2018, através da Resolução CNE/CES n ${ }^{\circ}$ 06/2018, na qual, entre outras modificações, estabelece o ingresso unificado na graduação. Há agora uma etapa comum durante a primeira metade do curso e, na segunda, uma etapa específica na qual os estudantes devem optar em seguir na licenciatura ou no bacharelado (BRASIL, 2018).

Para o presente ensaio pretendemos centralizar nossas análises e comentários a respeito da emergência, os limites, impre- 
As diretrizes curriculares nacionais da educação física de 2018 e as imprecisões em torno... Leonardo Trápaga Abib • Alan Goularte Knuth

cisões e as abordagens de saúde coletiva ${ }^{1}$ e ao Sistema Único de Saúde na referida resolução. O texto está estruturado em três partes: na primeira fazemos um resgate dos debates e das políticas na área da formação em saúde, em diálogo com a educação física; na segunda apresentamos o texto da resolução CNE/CES nº 06/2018 relacionado à saúde e discutimos o modo como ele aborda a saúde coletiva e o Sistema Único de Saúde; e, por fim, no terceiro tecemos nossas reflexões sobre as possíveis implicações das novas diretrizes curriculares para as discussões sobre saúde na formação inicial em educação física.

\section{Os debates sobre a formação para área da saúde e suas implicações para educação física}

Antes de ingressar na análise e reflexão a respeito das diretrizes curriculares da educação física, é preciso situar minimamente o/a leitor/a sobre o cenário da formação para área profissional da saúde e os debates que vêm ocorrendo desde a criação do Sistema Único de Saúde (SUS). Dentre as atribuições do sistema nacional de saúde, que constam na Constituição Federal brasileira de 1988, está a ordenação da formação de recursos humanos para o setor saúde, elemento que foi ratificado e detalhado na Lei orgânica 8.080/90 (BRASIL, 1990) que institui, entre outras funções, a organização e o funcionamento do sistema de saúde, reafirmando a relevância da formação para o setor saúde.

Um dos componentes importantes para modificação dos modos de trabalhar na saúde foi a criação do Programa Saúde da Família (BRASIL, 1997) - que mais tarde se tornaria Estratégia Saúde da Família (ESF) - baseado na experiência inovadora do Programa de Agentes Comunitários em Saúde (PACS). A partir da saúde da família, o modelo de atenção à saúde no SUS foi reorientado, tendo na Atenção Básica $(A B)$ o principal foco da mudança na organi-

\footnotetext{
1 Pode-se entender a saúde coletiva como campo de práticas e saberes interdisciplinar no qual busca-se produzir conhecimentos acerca do fenômeno saúde-doença enquanto processo social e histórico, assim como sobre o trabalho e as políticas públicas em saúde. Seus principais núcleos de saberes e práticas são a epidemiologia, as ciências sociais e humanas e a política/ planejamento/gestão (PAIM; ALMEIDA-FILHO, 1998).
} 
As diretrizes curriculares nacionais da educação física de 2018 e as imprecisões em torno... Leonardo Trápaga Abib • Alan Goularte Knuth

zação das redes de saúde e nas formas de trabalho e cuidado. Em certa medida, tal fato também contribuiu para se pensar acerca da construção de novas diretrizes curriculares para os cursos de graduação da área da saúde.

Para que tal movimento de renovação das diretrizes fosse possível, foi preciso pautar uma transição de um modelo até então hegemônico na formação em saúde, referenciado no modelo flexneriano e caracterizado pela sua estrutura conteudista, fragmentada e pautada por uma pedagogia da transmissão, para outro modelo de formação, pautado na tríade ensino-serviço-comunidade, na integralidade do cuidado e numa maior integração entre os ciclos básico e profissional (CAPOZZOLO et al., 2013).

No entanto, a implementação de tal modelo não vem sendo uma tarefa simples, dada a tradição, as disputas e as tensões inerentes à área da saúde. No estudo de Costa et al. (2018), no qual foram analisadas as diretrizes curriculares dos quatorze cursos de graduação da área da saúde, instituídas entre os anos de 2001 e 2004, foi apontada uma série de contradições internas nos documentos, mostrando haver neles um descompasso com as demandas do sistema público de saúde. Para as autoras, as diretrizes do referido período mantiveram, em parte, elementos do modelo tradicional de ensino e formação, indicando poucas inovações pedagógicas.

Tendo em vista as dificuldades para implementação de novos arranjos e desenhos curriculares, foram criadas, em nível federal, políticas de indução e fomento à experiências curriculares inovadoras e voltadas para o sistema público de saúde, como o Programa Nacional de Reorientação da Formação Profissional em Saúde, o PRÓ-Saúde I (BRASIL, 2005), visando atender a projetos vinculados aos cursos de medicina, enfermagem e odontologia (profissões que faziam parte da ESF), e o PRÓ-Saúde II (BRASIL, 2007a), que ampliou o programa para os demais cursos da área saúde².

2 Dados os desafios, potencialidades e dificuldades apresentadas ao longo dessas duas décadas, no processo de reorientação da formação em saúde, o Conselho Nacional de Saúde (CNS), por meio da Resolução 569/2017, construiu novos pressupostos, princípios e diretrizes comuns para as diretrizes curriculares nacionais dos cursos de graduação da área da saúde, indicando que ainda é preciso seguir produzindo estratégias formativas capazes de levarem em consideração as demandas do trabalho no sistema público de saúde, tendo em vista o fato de atravessarmos um novo momento de produção de reformas curriculares, como é o caso da educação física. 
As diretrizes curriculares nacionais da educação física de 2018 e as imprecisões em torno... Leonardo Trápaga Abib • Alan Goularte Knuth

De acordo com Albuquerque e Giffin (2008), apesar desse direcionamento ao SUS nas políticas de formação de trabalhadores para área da saúde, as disputas e tensões presentes no setor saúde, sob o avanço de reformas neoliberais, demarcaram contradições na educação e atuação profissional. Um processo formativo voltado para a especialização precoce, fragmentação no cuidado, competitividade do mercado, modelo empresarial e atendimento ao setor privado da saúde, impactam a formação em saúde, por vezes percorrendo o próprio discurso das políticas públicas. $O$ atendimento às imposições do mercado se apresenta, aberta ou discretamente, pressionando e disputando espaços na educação em nível superior, algo que prontamente se nota também na educação física.

Apesar de ter sido contemplada por editais do PRÓ-Saúde II e de já ter documentadas experiências de aproximação com a saúde pública, de modo geral a educação física manteve-se à parte dos processos do começo dos anos 2000, envolvendo reformulações curriculares com vistas à inserção de temas relacionados à saúde pública (FRAGA et al., 2012). Por outro lado, é preciso reconhecer que a educação física tem suas particularidades em relação aos demais cursos de graduação da área da saúde, fato que impõe algumas limitações para que se tenha uma formação mais próxima dos serviços públicos de saúde (por exemplo, o vasto campo profissional de atuação da área), o que implica na construção de uma série de estratégias para os cursos de graduação tentarem acomodar todos esses campos.

Os primeiros estudos que se propuseram a analisar o ensino da saúde na formação inicial em educação física apontaram que poucos cursos de graduação possuíam em seus projetos políticos pedagógicos disciplinas sobre saúde coletiva e saúde pública (ANJOS; DUARTE, 2009; PASQUIM, 2010). Outro elemento discutido nesses trabalhos foi a predominância das perspectivas tradicionais de análise e ensino da saúde, apresentando ênfase no modelo biomédico e nas correntes comportamentais da promoção de saúde. De acordo com a análise de Oliveira e Andrade (2016), a própria re- 
As diretrizes curriculares nacionais da educação física de 2018 e as imprecisões em torno... Leonardo Trápaga Abib • Alan Goularte Knuth

solução CNE/CES nº 07/2004, que institui as diretrizes curriculares nacionais da educação física, contribuíram pouco para a ampliação do debate sobre saúde na formação inicial, sendo que em seu texto não há qualquer tipo de menção ao SUS.

Já nos anos 2010, observa-se o aumento do número de equipes de Núcleo de Apoio à Saúde da Família (NASF)³, do Programa Academia da Saúde e dos Centros de Atenção Psicossocial (CAPS) no território nacional, bem como uma maior presença de profissionais de educação física atuando nesses - e em outros - serviços do SUS. No campo acadêmico também é possível perceber que o encontro da educação física com as teorias do campo da saúde coletiva - associada ao apoio oriundo de políticas de fomento a projetos nessa área - têm contribuído para uma ampliação de estudos a respeito do caráter social, político e relacional da saúde; para análises críticas de programas e ações governamentais; pesquisas sobre a atuação do profissional de educação física na saúde; e sobre diferentes práticas de cuidado (ANTUNES et al., 2020; NOGUEIRA; BOSI, 2017). Entretanto, mesmo com a emergência dessas experiências, o debate sobre saúde coletiva ainda é incipiente nos currículos da maioria dos cursos de educação física (LUIZ, 2016; SILVA; NICOES; KNUTH, 2021), que seguem mantendo a predominância e valorização dos conteúdos dos campos epistemológicos hegemônicos da área (biomédico e esportivo) em detrimentos de outros, gerando a fragmentação e hierarquização do conhecimento, além do fato de seguir enfatizando discussões que limitam a atuação do profissional de educação física ao âmbito privado e no combate à inatividade física, demonstrando ainda pouca articulação com os serviços públicos de saúde.

\section{A saúde nas novas diretrizes curriculares da educação física}

Diante do cenário vigente, no âmbito dos enfoques sobre saúde na formação inicial em educação física, criou-se uma expectati-

\footnotetext{
3 Em decorrência da portaria n².436/2017, que instituí a nova Política Nacional de Atenção Básica (BRASIL, 2017), atualmente essas equipes são chamadas de Núcleo Ampliado de Saúde da Família e Atenção Básica (NASF-AB).
} 
As diretrizes curriculares nacionais da educação física de 2018 e as imprecisões em torno... Leonardo Trápaga Abib • Alan Goularte Knuth

va para que as mudanças curriculares pudessem dar mais espaço para a saúde coletiva e para a aproximação com os serviços do SUS, além de induzir que a temática fosse discutida e debatida enquanto fenômeno complexo, resultante das condições de vida das populações (COSTA, 2019). Contudo, após uma série de leituras do referido documento, interpretamos que as DCNEF de 2018 não conseguem apontar para uma formação que ultrapasse os limites da intervenção via prescrição e orientação de atividades físicas centradas nos estilos de vida.

Nesse sentido, as recentes diretrizes curriculares para educação física, instituídas pela Resolução CNE/CES nº 06/2018, trouxeram modificações formais a respeito da saúde em relação às diretrizes da Resolução CNE/CES nº 07/2004, muito embora não tenham apresentado articulação com as políticas relativas à formação na área da saúde apontadas anteriormente neste ensaio. No entanto, a principal diferença acaba sendo a divisão da graduação em duas etapas formativas, sendo a primeira chamada de "comum" e a segunda de "específica", na qual os/as estudantes, após concluírem a primeira etapa, optam em cursar licenciatura ou bacharelado (BRASIL, 2018).

O documento das DCNEF inicia seu texto classificando a educação física como área de conhecimento e intervenção profissional, tendo como seu objeto de estudo e aplicação "a motricidade ou movimento humano, a cultura do movimento corporal, com foco nas diferentes formas e modalidades do exercício físico, da ginástica, do jogo, do esporte, das lutas e da dança" (BRASIL, 2018, p. 1). A composição do que foi apresentado como objeto busca reunir concepções divergentes, como motricidade, movimento humano e cultura do movimento corporal. O que não está explícito é se tal caracterização reflete um interesse em considerar as distintas concepções ou uma limitação conceitual ao reuni-las. Na hipótese de expressar diferentes concepções, poderiam ser incluídas a cultura corporal de movimento e as práticas corporais. Esta lacuna não deveria ocorrer, afinal estamos diante das DCN da área. Um segundo ponto, aí certamente impreciso, é a ausência de regularida- 
As diretrizes curriculares nacionais da educação física de 2018 e as imprecisões em torno... Leonardo Trápaga Abib • Alan Goularte Knuth

de do referido objeto, pois ao retomá-lo ao longo do documento, adiciona-se a "atividade física" (BRASIL, 2018, p. 2, p. 4 e p. 5), além de um "e" entre motricidade e movimento humano (BRASIL, 2018, p. 5), induzindo ao entendimento de sinônimos. Desse modo, as DCNEF não conseguem estabelecer com precisão o objeto de estudo e a aplicação da educação física. De modo complementar também identificamos que o documento carrega em si distintas perspectivas de saúde, fato que dificulta o entendimento concreto da proposta curricular, abrindo brechas para inúmeras interpretações e usos (inclusive antagônicos). Além disso, identificamos a falta de referências em relação às diretrizes e princípios oriundos das políticas de formação na área da saúde.

Em vista ao atendimento das necessidades sociais nos campos da saúde, educação, cultura, treinamento físico e lazer, as diretrizes apresentam e propõem eixos, conteúdos, conhecimentos a serem trabalhados em cada etapa do curso. Para esta seção iremos discutir como a saúde é abordada ao longo das novas DCNEF em suas distintas etapas e especificidades.

\section{Etapa Comum}

No texto das DCNEF a etapa comum está definida como "núcleo de estudos da formação geral, identificador da área de Educação Física, a ser desenvolvido em 1.600 (mil e seiscentas) horas referenciais, comum a ambas as formações" (BRASIL, 2018, p. 2).

Nesta etapa, de acordo com as diretrizes, os/as estudantes deverão ter contato com os conhecimentos biológicos, psicológicos e socioculturais relacionados ao ser humano e aos objetos de estudo e intervenção da área. Também se prevê que durante a etapa comum se trabalhe com a iniciação à pesquisa científica, aos valores éticos da profissão e a elementos ligados aos campos de saberes e práticas da educação física. Nesse ínterim também cabe à etapa atividades sobre "diagnóstico e avaliação, estratificação de risco, variáveis de prescrição do exercício, meio ambiente e sus- 
As diretrizes curriculares nacionais da educação física de 2018 e as imprecisões em torno... Leonardo Trápaga Abib • Alan Goularte Knuth

tentabilidade, diversidade cultural, diferenças individuais e outros" (BRASIL, 2018, p. 2). Aqui é possível localizar alguns conteúdos que sugerem uma aproximação aos núcleos de saberes da saúde coletiva - para além da prescrição de exercícios -, como diagnóstico, avaliação, meio ambiente e sustentabilidade. Em relação aos conhecimentos - biológicos, psicológicos e socioculturais - as diretrizes não preveem uma distribuição específica, deixando aberta a interpretação para as instituições decidirem como trabalharão com eles.

Um dos pontos mais discutidos no âmbito da formação em saúde é a aproximação com os serviços e as comunidades desde o começo da graduação (CAPOZZOLO et al., 2013). Nas DCNEF a etapa comum abre uma possibilidade para tal tipo de movimento:

A etapa comum deverá proporcionar atividades acadêmicas integradoras - disciplinas de aproximação ao ambiente profissional - por se tratar de uma etapa comum, estima-se que as atividades previstas por esse artigo sejam direcionadas aos diversos campos de atuação que as diretrizes mencionaram anteriormente - esporte de alto rendimento, lazer e cultura, educação, saúde (BRASIL, 2018, p. 3).

Contudo é preciso observar que, dadas as peculiaridades da área e seu largo campo de atuação, essa aproximação não é bem detalhada no documento, dando a entender que a distribuição dessas atividades acadêmicas integradoras ficará a cargo das instituições, ou seja, para que os estudantes possam vir a conhecer os serviços públicos de saúde já na etapa comum, dependerá da articulação das IES com essas instituições de saúde e outros setores.

\section{Etapa Específica - Licenciatura}

As etapas específicas - licenciatura e bacharelado - deverão ser desenvolvidas em 1.600 (mil e seiscentas) horas referenciais, 
As diretrizes curriculares nacionais da educação física de 2018 e as imprecisões em torno... Leonardo Trápaga Abib • Alan Goularte Knuth

incluindo os estágios obrigatórios e o trabalho de conclusão de curso. Na redação das DCNEF percebe-se que a formação desta etapa específica está voltada exclusivamente para a atuação na escola, de modo a haver pouca margem para que os/as estudantes que optarem por essa formação acessem discussões que extrapolem o campo educacional. O texto mostra-se mais articulado com as políticas de educação, como as diretrizes curriculares para formação de professores, entre outras.

A etapa específica - licenciatura, em seu artigo 15, trabalha com a proposição de conteúdos programáticos que devem, respeitando a diversidade e autonomia das instituições, ser abordados na formação de modo a contemplar os diferentes níveis da educação básica (educação infantil, ensino fundamental, ensino, médio, educação de jovens e adultos) como: política e organização do ensino básico, introdução à educação física escolar, didática e metodologia de ensino da educação física escolar, entre outras.

A saúde e a escola, ainda que não constem nesta etapa específica das DCNEF, podem se aproximar a partir de algumas possibilidades: a operacionalização teórico-prática dos conceitos de saúde desde a aula de educação física nos diferentes níveis de ensino, com vistas a elaboração de uma concepção de saúde crítica; os efeitos das diferentes mídias e da internet ao relacionar a cultura corporal à saúde, especialmente com direcionamento ao público jovem; políticas públicas que utilizem a comunicação e os temas saúde e educação física em seus discursos; a articulação que diversas políticas públicas de saúde fazem entre dispositivos dos territórios, como as Unidades Básicas de Saúde e escolas; programas e políticas intersetoriais, como o Programa Saúde na Escola (BRASIL, 2007b), que colocam objetivamente a escola, saúde e educação física em interlocução; a busca por uma educação que indique a importância da saúde como direito social e não a simplifique ao nível de um bem de consumo. Nesse caso, gostaríamos de ressaltar que a saúde, seja no campo atitudinal, seja no conceitual, é um dos conteúdos potentes para as aulas de educação física na escola, desde que abordada criticamente e sistematizada pedago- 
As diretrizes curriculares nacionais da educação física de 2018 e as imprecisões em torno... Leonardo Trápaga Abib • Alan Goularte Knuth

gicamente para atender as demandas daquele espaço. Para isso seria pertinente abordar os saberes e práticas da saúde coletiva na etapa específica da licenciatura, de modo a contribuir para a discussão sobre o tema e suas possibilidades na escola.

\section{Etapa Específica - bacharelado}

É na etapa específica - bacharelado que os conhecimentos relacionados à saúde emergem com mais vigor nas DCNEF. De acordo com o texto, essa etapa deverá ser estruturada de modo a qualificar os/as estudantes para a intervenção profissional "em treinamento esportivo, orientação de atividades físicas, preparação física, recreação, lazer, cultura em atividades físicas, avaliação física, postural e funcional, gestão relacionada com a área de Educação Física" (BRASIL, 2018, p. 5). Nesse trecho não se fala abertamente da natureza dos campos de atuação, no entanto, parece-nos evidente que nele há uma demarcação de território de atuação ampla. Alguns dos objetivos elencados pelas diretrizes para o bacharelado e que podem apresentar alguma aproximação com as abordagens da saúde coletiva são:

[...] b) pesquisar, conhecer, compreender, analisar e avaliar a realidade social para nela intervir acadêmica e profissionalmente, por meio das manifestações e expressões da motricidade humana e movimento humano, cultura do movimento corporal, atividades físicas, tematizadas, com foco nas diferentes formas e modalidades do exercício físico, da ginástica, do jogo, do esporte, das lutas, da dança, visando à formação, à ampliação e enriquecimento cultural da sociedade para a adoção de um estilo de vida fisicamente ativo e saudável [...] c) intervir acadêmica e profissionalmente de forma fundamentada, deliberada, planejada e eticamente balizada nos campos da prevenção, promoção, proteção e reabilitação da saúde [...] (BRASIL, 2018, p. 5-6). 
As diretrizes curriculares nacionais da educação física de 2018 e as imprecisões em torno... Leonardo Trápaga Abib • Alan Goularte Knuth

Para além disso, o texto demonstra um caráter de sincretismo sanitário, no qual diferentes abordagens e perspectivas de saúde são mobilizadas em torno dos enunciados, fato que pode indicar como são articuladas as tensões e disputas internas da área quando o assunto é saúde (DAMICO; KNUTH, 2014; MARTINEZ et al., 2013). É possível localizar essas distintas influências no modo como se utiliza ações do campo da saúde coletiva (analisar e avaliar realidade social) com ações típicas da vertente tradicional da promoção da saúde (adoção de um estilo de vida fisicamente ativo $e$ saudável). $\mathrm{O}$ fragmento que aciona a "prevenção, promoção, proteção e reabilitação da saúde" pode dizer respeito tanto a uma aproximação com o léxico presente nas políticas de saúde quanto à demarcação profissional corporativa. Em outros excertos presentes no documento ainda constam os seguintes objetivos:

[...] f) participar, assessorar, coordenar, liderar e gerenciar equipes multiprofissionais de discussão, de definição, de planejamento e de operacionalização de políticas públicas e institucionais nos campos da saúde, do lazer, do esporte, da educação não escolar, da segurança, do urbanismo, do ambiente, da cultura, do trabalho, dentre outros [...] g) diagnosticar os interesses, as expectativas e as necessidades das pessoas (crianças, jovens, adultos, idosos, pessoas com deficiência, de grupos e comunidades especiais) de modo a planejar, prescrever, orientar, assessorar, supervisionar, controlar e avaliar projetos e programas de atividades físicas e/ou esportivas e/ou de cultura e de lazer. (BRASIL, 2018, p. 6).

Nos fragmentos acima há uma indicação de dois pontos importantes para saúde coletiva e a formação em saúde, que são a participação em equipes multiprofissionais e o planejamento de políticas públicas (NOGUEIRA; BOSI, 2017). Tais características ganham enfoque novamente na descrição do eixo saúde (a etapa do bacharelado é constituída por três eixos: saúde, esporte e lazer e cultura): 
As diretrizes curriculares nacionais da educação física de 2018 e as imprecisões em torno... Leonardo Trápaga Abib • Alan Goularte Knuth

Saúde: políticas e programas de saúde; atenção básica, secundária e terciária em saúde, saúde coletiva, Sistema único de Saúde, dimensões e implicações biológica, psicológica, sociológica, cultural e pedagógica da saúde; integração ensino, serviço e comunidade; gestão em saúde; objetivos, conteúdos, métodos e avaliação de projetos e programas de Educação Física na saúde (BRASIL, 2018, p. 6).

O texto do eixo saúde quando comparado ao restante dos fragmentos da etapa do bacharelado demonstra maior conexão com as demandas relacionadas aos saberes e práticas da saúde coletiva, sendo o único momento no qual se lê nas diretrizes uma menção ao SUS; termos como integração ensino, serviço e comunidade, gestão em saúde, atenção básica são comuns no léxico das políticas públicas de saúde e de formação, como já foi comentado neste ensaio. Nesse sentido, elementos como maior participação de docentes, pesquisadores/as e estudantes de educação física, assim como maior presença de profissionais da área atuando nos serviços públicos de saúde e no âmbito da gestão pública, podem ter contribuído para essa inserção na nova resolução. Contudo é preciso comentar que tal ponto aparece de certo modo isolado ou desconexo do restante do texto apresentado nas diretrizes, fato que pode ilustrar as formas de tensionamento devido ao predomínio de uma postura privatista e individual da área.

Em contraponto à tal lógica, ressaltamos a relevância do núcleo de saberes e práticas da "educação física \& saúde coletiva" para a formação inicial. Nogueira e Bosi (2017) argumentam que esse núcleo pode se efetivar na articulação entre epidemiologia, ciências sociais e humanas, política e gestão pública. Nesse caso muitos/as docentes e estudantes podem se perguntar a respeito da relevância da saúde coletiva para intervenção do profissional de educação física, já que ela não oferta ferramentas tão diretas para a prescrição de exercícios físicos. A conexão entre educação física e saúde coletiva nos últimos anos tem contribuído para aproximação da área junto aos serviços públicos de saúde e às comunidades atendidas por eles, assim como para uma maior sen- 
As diretrizes curriculares nacionais da educação física de 2018 e as imprecisões em torno... Leonardo Trápaga Abib • Alan Goularte Knuth

sibilização dos/as estudantes no que se refere à saúde enquanto uma questão também política e afetiva, o que exige do futuro profissional um olhar e um cuidado mais acolhedor e diversificado para com os sujeitos. Também podemos argumentar que as redes construídas entre educação física e saúde coletiva têm permitido à área produzir análises e avaliações de políticas públicas de saúde que têm contribuído para o aprimoramento das mesmas e ainda para construção de novas ações no âmbito público. No entanto, cabe aqui ressaltar que em tal relação também há divergências e diferenças em torno dos modos de pensar a inserção profissional, a criação e condução de políticas públicas, o ensino na graduação e as práticas de cuidado, o que nos impede de afirmar que essa interação ocorra de forma homogênea ou tranquila (BOSl; NOGUEIRA, 2017).

Pensando a respeito disso, acreditamos que este não seja o momento de considerar que essa inserção de elementos da saúde coletiva e do SUS é definitiva, afinal é preciso entender o cenário e o processo de construção das DCNEF. Particularmente, não estamos em acordo com a nova proposta curricular, tampouco que a continuação da divisão entre licenciatura e bacharelado seja a melhor opção, ainda que o artigo 30 coloque que as IES possam admitir a "dupla formação dos matriculados em bacharelado e licenciatura" (BRASIL, 2018, p. 8).

Mais um elemento que problematizamos nas DCNEF diz respeito a uma certa fragilidade em como a saúde é compreendida na educação física. Parece-nos que ao eixo saúde é permitido uma inflação de temas que busca fundir práticas do treinamento físico realizado em academias e clubes, por exemplo, com as práticas que fazem a educação física funcionar no SUS. Considerando que as IES colocarão os currículos em funcionamento, poderá ocorrer uma sobreposição do conceito de saúde, no sentido do treinamento físico, e a não observância das particularidades que a saúde coletiva e o SUS colocam para a educação física. Dito de outra forma, o treinamento físico foi historicamente associado à saúde na educação física, enquanto a saúde coletiva e o SUS representam 
As diretrizes curriculares nacionais da educação física de 2018 e as imprecisões em torno... Leonardo Trápaga Abib • Alan Goularte Knuth

concepções de saúde mais recentemente mobilizadas na formação inicial. São saberes distintos e importantes, mas não deveriam ser reduzidos a um eixo comum. Se mantidos no eixo (saúde), deveriam ter suas particularidades explícitas e não fundidas. É possível também a ocorrência destas deturpações nos eixos de esporte, cultura e lazer, mas elas escapam ao escopo deste texto.

Analisando o texto presente na etapa específica do bacharelado, não fica claro, como na licenciatura, quais serão os conteúdos programáticos da formação. Embora a resolução afirme que o estágio deva ser oferecido de forma articulada com as políticas e as atividades de extensão da instituição, não há como garantir que esses serão realizados, por exemplo, em serviços públicos de saúde. A resolução também apresenta de maneira tímida alguns pontos relacionados à pesquisa e extensão, sendo a segunda mais acionada justamente nos artigos referentes aos estágios curriculares e ao plano comum de formação.

Por fim, a presente Resolução parece ter desconsiderado o acúmulo recente de pesquisas e relatos de experiências que mostram que o trabalho do profissional de educação física no SUS pode se dar de diferentes maneiras na $A B$, na saúde mental, na gestão e planejamento de políticas públicas (CARVALHO; NOGUEIRA, 2016; FURTADO et al., 2017; FERREIRA et al., 2017; OLIVEIRA; WACHS, 2019), já que não conseguiu ao longo de seu texto vislumbrar uma formação para além da prescrição de atividade física centrada nos estilos de vida.

\section{Considerações transitórias}

A resolução CNE/CES n 6/2018 trouxe a saúde coletiva e o Sistema Único de Saúde para as diretrizes curriculares da educação física, o que, em tese, seria por si um passo pertinente se comparado à resolução CNE/CES nº 7/2004 em que essas temáticas não estavam previstas. Porém, não estamos certos de que 
As diretrizes curriculares nacionais da educação física de 2018 e as imprecisões em torno... Leonardo Trápaga Abib • Alan Goularte Knuth

seja o suficiente, dadas as fragilidades, contradições e imprecisões presentes no documento.

Em nossas análises notamos que o presente documento carrega em si distintas perspectivas e abordagens de saúde, elemento que não permite entender o quanto e de que forma se pretende enfatizar o debate sobre SUS e a saúde coletiva nos cursos de educação física. Embora tenha incluído temáticas sobre saúde, a resolução não demonstra articulação com as políticas de formação na área da saúde, deixando lacunas acerca da integração ensino-serviço-comunidade, a interprofissionalidade, noções de cuidado e perspectivas de atuação profissional, temas tão importantes nas discussões sobre formação para área profissional da saúde.

Nosso posicionamento é que tais lacunas seriam diluídas caso ocorresse uma demarcação sobre qual projeto de saúde as DCNEF pretendem responder quando acionam a saúde coletiva e o SUS. A trajetória conceitual e histórica do movimento sanitário, do campo de práticas e saberes da Saúde Coletiva (ao qual nos filiamos) e do SUS, como um marco de proteção social, nos direcionam para uma saúde na perspectiva do direito social, marcada por processos socioculturais e biológicos, tramada na cultura e ainda amplamente desigual em termos de acesso em nosso país. Sabedores dos projetos em disputa com os quais convivemos, há também uma saúde capturada pelos mandatos neoliberais e sitiada numa ilha de privilégios, em tornos de bens e serviços, superficialmente sustentada na concepção das motivações, do empreendedorismo e da meritocracia. Em nome da saúde como mercadoria, por vezes escamoteada por reproduzir terminologias como estas que agora aparecem formalmente nas DCNEF, muitos interesses corporativos e do âmbito do atendimento de poucos indivíduos ou grupos podem prevalecer. Para nos contrapormos a esse viés, sustentamos que a educação física se fundamente em uma saúde com o princípio do humanismo radical.

Diante de tal quadro, trazemos aqui alguns questionamentos para o debate e futuras avaliações e análises: a saúde coletiva e a saúde pública serão tratadas dentro de uma disciplina específica 
As diretrizes curriculares nacionais da educação física de 2018 e as imprecisões em torno... Leonardo Trápaga Abib • Alan Goularte Knuth

e/ou serão temas transversais ao longo do currículo? A saúde coletiva e saúde pública serão reduzidas à noção de saúde colocada no âmbito do treinamento físico? Como se dará o diálogo com a gestão e os serviços de saúde? Quais estratégias e metodologias serão mobilizadas para instigar os alunos a pensarem sobre a prática profissional e a pesquisa no contexto do SUS? Haverá espaço para ações de formação interprofissional junto a outros cursos da área da saúde? Como serão feitas as discussões sobre saúde no currículo da licenciatura? Qual, afinal, é o objeto de estudo e intervenção da educação física? Com esses questionamentos não pretendemos defender que os currículos de educação física trabaIhem única e exaustivamente o tema da saúde, afinal entendemos que a área é diversa e os/as estudantes precisam conhecer os demais saberes e práticas pertinentes à educação física. Em tempo, cabe também nos colocarmos ao lado da autonomia universitária e compreender que serão as IES que darão forma ao exposto nas DCNEF.

O currículo enquanto espaço de diálogo, disputa, de movimento, jamais terá condições de abarcar a grande maioria dos conhecimentos produzidos e relevantes para atuação profissional. Não há carga horária que dê conta de tal desafio. No entanto, para além dos detalhes técnicos, acreditamos que ainda seja possível produzir "um comum" (PASSOS; CARVALHO, 2015) para essa interface "formação em educação física \& saúde", a partir da construção e implementação de projetos políticos pedagógicos amparados por princípios e diretrizes que visem a valorização do espaço coletivo e público, capaz de fortalecer o compromisso ético-político com os trabalhadores e usuários do SUS.

\section{Referências}

ALBUQUERQUE, V. S; GIFFIN, K. M. Globalização capitalista e formação profissional em saúde: uma agenda necessária ao ensino superior. Trabalho Educação Saúde, Rio de Janeiro, v. 6, n. 3, p. 519-538, 2008. 
As diretrizes curriculares nacionais da educação física de 2018 e as imprecisões em torno... Leonardo Trápaga Abib • Alan Goularte Knuth

ANJOS, T. C.; DUARTE, A. C. G. O. A Educação Física e a estratégia de saúde da família: formação e atuação profissional. Physis, Rio de Janeiro, v. 19, n. 4, p. 1127-44, 2009.

ANTUNES, P.C. et al. Panorama da produção científica do GTT Atividade Física e Saúde do CBCE: aproximações com a saúde pública. In: WACHS, F.; LARA, L.; ATHAYDE, P. (Orgs). Ciências do esporte, educação física e produção do conhecimento em $\mathbf{4 0}$ anos de CBCE: Atividade física e saúde. Natal: EDUFRN, 2020, p. 79-100.

BRASIL. Resolução CNE/CES nº6 de 18 de dezembro de 2018. Institui as Diretrizes Curriculares Nacionais para os cursos de graduação em Educação Física. Brasília, DF, 2018.

BRASIL. Portaria interministerial n. 3.019, de 26 de novembro de 2007. Institui o Programa Nacional de Reorientação da Formação Profissional em Saúde - Pró-saúde II. Brasília, DF, 2007a.

BRASIL. Decreto n. 6.286, de 5 de dezembro de 2007. Institui o Programa Saúde na Escola - PSE, e dá outras providências. Diário Oficial da União, Poder Executivo, Brasília, DF, 5 dez. 2007b.

BRASIL. Portaria interministerial $\mathbf{n}$ 2.101, de 3 de novembro de 2005. Institui o Programa Nacional de Reorientação da Formação Profissional em Saúde - Pró-Saúde - para os cursos de graduação em Medicina, Enfermagem e Odontologia. Brasília, DF, 2005.

BRASIL. Resolução CNE/CES nº 07, de 31 de março de 2004. Institui as Diretrizes Curriculares Nacionais para os cursos de graduação em Educação Física, em nível superior de graduação plena. Brasília, DF, 2004.

BRASIL. Saúde da família: uma estratégia para a reorientação do modelo assistencial. Brasília: Ministério da Saúde; 1997.

BRASIL. Lei $\mathbf{n}^{\circ} \mathbf{8 . 0 8 0}$ de 19 de setembro de 1990. Dispõe sobre as condições para a promoção, proteção e recuperação da saúde, a organização e o funcionamento dos serviços correspondentes e dá outras providências. Diário Oficial da União 1990; 19 set. 
As diretrizes curriculares nacionais da educação física de 2018 e as imprecisões em torno... Leonardo Trápaga Abib • Alan Goularte Knuth

CAPOZZOLO, A. A, et al. Experiência, produção de conhecimento e formação em saúde. Interface, Botucatu, v. 17, n. 45, p. 357370, 2013.

CARTA da Educação Física ao Conselho Nacional de Educação. 2019 Set [acessado 2020 Mai 28]. Disponível em: http://www. cbce.org.br/upload/biblioteca/MO\%C3\%87\%C3\%830\%20DE\%20 APOIO\%20\%C3\%80\%20CARTA\%20AO\%20CNE.pdf.

CARVALHO, F. F. B.; NOGUEIRA, J. A. D. Práticas corporais e atividades físicas na perspectiva da Promoção da Saúde na Atenção Básica. Ciência Saúde Coletiva, Rio de Janeiro, v. 21, n. 6, p. 1829-38, 2016.

COSTA, D. A. S. et al. Diretrizes curriculares nacionais das profissões da Saúde 2001-2004: análise à luz das teorias de desenvolvimento curricular. Interface, Botucatu, v. 22, n. 67, p. 1183-95, 2018.

COSTA, F. Novas diretrizes curriculares para os cursos de graduação em Educação Física: oportunidades de aproximações com o SUS? Revista Brasileira de Atividade Física e Saúde, Pelotas, v. 24, n. 1, e0067, 2019.

DAMICO, J. G. S.; KNUTH, A. G. O des(encontro) das práticas corporais e atividade física: hibridizações e borramentos no campo da saúde. Movimento, Porto Alegre, v. 20, n. 3, p. 329-350, 2014. FERREIRA, L. A. dos S. et al. Entre a composição e a tarefa: estudo de caso sobre a inserção da educação física em um serviço de saúde mental. Revista Brasileira Ciências Esporte, Brasília, v. 39, n. 2, p. 176-182, 2017.

\section{FINOQUETO, L. C. P. Entre Licenciatura e Bacharelado em}

Educação Física: Reformas no Ensino Superior e a Constituição de Identidades dos Profissionais de Educação Física da ESEF/ UFPel. 2013. 260f. Tese (Doutorado em Educação) - Universidade Federal de Pelotas, Pelotas, 2013.

FRAGA, A. B. et al. Políticas de formação em educação física e saúde coletiva. Trabalho Educação Saúde, Rio de Janeiro, v. 10, n. 3, p. 367-386, 2012. 
As diretrizes curriculares nacionais da educação física de 2018 e as imprecisões em torno... Leonardo Trápaga Abib • Alan Goularte Knuth

FURTADO, R. P. et al. Desinstitucionalizar o cuidado e institucionalizar parcerias: desafios dos profissionais de Educação Física dos CAPS de Goiânia em intervenções no território. Saúde e Sociedade, São Paulo, v. 26, n. 1, p. 183-195, 2017.

LUIZ, A. R. Ensino sobre saúde pública e coletiva nos cursos de graduação em educação física no Brasil. 2016. 89f. Tese (Doutorado em Ciências da Saúde) - Universidade Federal de Goiás, Goiânia, 2016.

MARTINEZ, J. F. N. et al. Práticas corporais e SUS: tensões teóricas e práticas. In: FRAGA, A. B.; CARVALHO, Y. M.; GOMES, I. M. (Orgs). As práticas corporais no campo da saúde. São Paulo: Hucitec, 2013, p. 139-77.

MAIA, J. C. A.; SACARDO, M. S. A produção científica sobre as Diretrizes Curriculares para a Educação Física (DCNEF): determinações históricas e implicações para formação e intervenção profissional. Movimento, Porto Alegre, v. 26, n. 1, e26037, 2020.

NOGUEIRA, J. A. D.; BOSI, M. L. M. Saúde Coletiva e Educação Física: distanciamentos e interfaces. Ciência Saúde Coletiva, Rio de Janeiro, v. 22, n. 6, p. 1913-22, 2017.

OLIVEIRA, R. C.; ANDRADE, D. R. Formação profissional em educação física para o setor da saúde e as diretrizes curriculares nacionais. Pensar a Prática, Goiânia, v. 19, n. 4, p. 1-13, 2016.

OLIVEIRA, B. N.; WACHS, F. Educação física, atenção primária à saúde e organização do trabalho com apoio matricial. Revista brasileira de ciências do esporte, Brasília, v. 41, n. 2, p. 183-189, 2019. PAIM, J. S.; ALMEIDA-FILHO, N. Saúde coletiva: uma "nova saúde pública" ou campo aberto a novos paradigmas? Rev. Saúde Pública, São Paulo, v. 32, n. 4, p. 299-316, 1998.

PASSOS, E.; CARVALHO, Y. M. A formação para o SUS abrindo caminhos para a produção do comum. Saúde e Sociedade, São Paulo, v. 24, n. 1, p. 92-101, 2015.

PASQUIM, H. M. A saúde coletiva nos cursos de graduação em Educação Física. Saúde e Sociedade, São Paulo, v. 19, n. 1, p. 193-200, 2010. 
As diretrizes curriculares nacionais da educação física de 2018 e as imprecisões em torno... Leonardo Trápaga Abib • Alan Goularte Knuth

SILVA, V. T. da; NICOES, C. R.; KNUTH, A. G. Saúde coletiva e saúde pública no currículo dos cursos de educação física: uma revisão sistemática. Pensar a Prática, Goiânia, v. 24, e61062, 2021.

SOUZA NETO S. et al. Conflitos e tensões nas diretrizes curriculares de educação física: o campo profissional como um espaço de lutas e disputas. Pensar a Prática, Goiânia, v. 19, n. 4, p. 734-746, 2016.

\section{Publisher}

Universidade Federal de Goiás. Faculdade de Educação Física e Dança. Publicação no Portal de Periódicos UFG. As ideias expressadas neste artigo são de responsabilidade de seus autores, não representando, necessariamente, a opinião dos editores ou da universidade. 